\title{
Measuring what Counts: An Exploratory Study about the Key Challenges of Measuring Design Thinking Activities in Digital Innovation Units
}

\author{
Selina Mayer \\ Hasso-Plattner-Institute \\ University of Potsdam \\ Selina.Mayer@hpi.de
}

\author{
Thomas Haskamp \\ Hasso-Plattner-Institute \\ University of Potsdam \\ Thomas.Haskamp@hpi.de
}

\author{
Danielly de Paula \\ Hasso-Plattner-Institute \\ University of Potsdam \\ Danielly.DePaula@hpi.de
}

\begin{abstract}
Digital Innovation Units (DIUs) have become an important vehicle for digital innovation and the exploration of new ventures, often applying Design Thinking (DT). However, scholars lack knowledge about how to measure these activities from the perspective of both DIUs and DT. To understand the key challenges involved, an exploratory qualitative research design and a grounded theory approach were adopted to analyze data obtained from interviews conducted with 20 DIU members. Our findings identify eight challenges around the topic of misalignment between the DIUs' objectives and how their activities are assessed by using metrics. The rich descriptions provided in this study deepen our understanding of the challenges involved in measuring DIUs' activities, and provide the basis for future developments to monitor and steer their innovation activities more meaningfully to guide resource allocation.
\end{abstract}

\section{Introduction}

The fast pace of digital innovation presents a game-changer for today's firms [1], [2]. To remain competitive, incumbent firms often invest in a variety of development activities aimed at transforming their core offerings to incorporate numerous connected digital products and services, even developing new business models [3], [4]. The adoption of Digital Innovation Units (DIUs), which are tasked with the exploration of new business opportunities, is receiving growing attention from both practitioners and scholars [5]. These units, which promise to develop innovative and customer-centric products and services [8], [9], embrace agile work practices for their explorative endeavors, such as Design Thinking (DT) [6], [7]. While both DIUs and DT activities appear to be successful in their endeavor to deliver digital innovations [10], [11], there is little robust evidence linking their performance to their impact [12], [13], which suggests a lack of appropriate measurement systems.

Scholars previously viewed performance management as detrimental to innovation [14], but today's scholars agree on the importance of performance measurement systems for a better information exchange between stakeholders in the innovation process [15], [16]. Although the literature features a range of performance measurement systems, such as the Balanced Scorecard [17], the majority of the established metrics tend to incentivize incremental innovations over the more difficult-to-measure radical innovations, as they are easier to achieve [18], [19].

Researchers, therefore, call for specifically designed performance measurement systems that can target the more radical and exploratory innovation activities [15]. Developing such a measurement system for innovation endeavors is, however, very challenging, in particular when it comes to capturing the causal effects of the creative activities of the explorative front-end phase, where teams explore areas of high uncertainty [20]. While earlier research on creativity has acknowledged the importance of clear goal setting and feedback mechanism, measurement remains very complex and is hard to adapt [21]. In this exploratory phase, DIUs use various practices for their innovation endeavors, DT being one of the frequently used agile methods [6], [11].

Another issue highlighted by research is the limited ability of existing metrics to reflect the shift initiated by digital innovations towards more heterogeneous, flexible, and user-driven business models [22]-[24]. Investigating these challenges faced by DIUs is, however, fundamental to enable them to deliver more 
exploratory innovations and help them navigate unchartered territory [5].

To summarize our research gap, although scholars are aware of the limitations of current measurement systems for early exploratory phases, little is known about this in the specific context of DIUs. In particular, we lack understanding of the challenges faced by companies confronted with the task of measuring their exploratory activities in DIUs, specifically DT.

As long as they lack suitable measurement systems, companies will continue to struggle with fully assessing, and improving their innovation efforts, which could result in efficiency losses. It is important, therefore, to better understand these issues and propose solutions on how to address them. This paper, then, aims to investigate the challenges that companies face when confronted with the task of measuring innovation efforts in DIUs. Thus, we pose our research question.

$R Q$ : "What are the key challenges involved in measuring Design Thinking related to digital innovation endeavors in DIUs?"

To answer this question, 20 exploratory semi-structured interviews with participants from DIUs were conducted. We present rich descriptions of eight challenges based on subareas that practitioners experienced in DIUs. These areas occur around the misalignment between the objectives and scope of DIUs and the measurement system. This contribution provides a starting point for the development of measurement approaches that can consider these challenges, and to helping firms enhance the effectiveness and efficiency of their resource allocation to digital innovation development activities [5].

\section{Theoretical Background}

This section sets out the theoretical background underpinning the phenomenon of DIUs and their practices, such as DT and what we know about the challenges of measuring these.

\subsection{Digital Innovation (Unit)}

The emergence of digital innovation, understood by Nambisan et al. as "the creation of (and consequent change in) market offerings, business processes, or models that result from the use of digital technology" [1, p. p.224], presents a fundamental shift in the management of innovation [1], [2], [25]. As a consequence, business models shift from product to services [22] and firms need to adjust their processes in terms of speed and flexibility [22], [26]. Alongside this strategic shift, firms have also undertaken structural steps, embedding multiple internal units tasked with digital innovation endeavors [5]. Understanding these units as an organizational setup aimed at driving digital innovation, DIUs have gained increasing attention as a research topic [5], [6]. Despite their high relevance, current literature on DIUs is limited due to its recent emergence [5]. Based on the existing literature, we understand a DIU to be a dedicated organizational unit tasked with the exploration of new digital technologies and subsequently, the development of new digital products, services, and business models for existing or new markets [5], [27].

This broad description shows that there are not yet any fixed characteristics and definitions of DIUs. So far, DIUs are often seen as internal but separate entities, sometimes also referred to as Digital Innovation Labs [6], [7]. However, bearing in mind the above-mentioned diversification of (digital) innovation initiatives in organizations, we deliberately adopted a broad definition, to include all units, whether internally or external located.

\subsection{DIU Practices: Design Thinking}

To enact their exploratory orientation towards digital innovation, DIUs rely on agile work practices such as DT and scrum [6], [11]. While DT practices are more commonly used for the exploratory part of software projects, scrum practices are adopted in later stages for the actual development of the software [28]. As we are investigating DIUs and their exploratory intent, we focus on DT practices, which are also valued by firms for their ability to increase customer proximity [9], [29]. Our focus was supported through our early interviews which confirmed the use of DT as a common practice for exploratory activities.

Design Thinking can be understood as a set of methods, as a process, or as a mindset [30]. For this study, we follow Tim Brown's understanding of DT as a set of methods that aims to combine "people's needs with what is technologically feasible and what a viable business strategy can convert into customer value and market opportunity"'[8, p. 86]. Thus, we define design thinking-related digital innovation endeavors as activities where the DT methods (e.g. customer journey, interview, brainstorming techniques, etc.) are applied and understood in the context of process and mindset [30]. Literature shows that DT is used in firms to explore and develop radically new ideas through unconstrained thinking [13], or to create new ideas in well-established markets [30] whether to gain a competitive advantage [31] or to prepare managers for 
dynamic contexts [32]. Although DT has been of increasing interest to practitioners and academics, measurements on DT activities are scarce [10], [13]. Notable exceptions include, for example, efforts to measure the DT process in educational settings, to monitor lexical systems or to monitor progress [33], [34]. However, measurement systems and theoretical frames of where added value can be expected are seen as difficult or rather non-existent [10], [13].

\subsection{DIU Measurement Systems}

Following well-known scholars, a measurement system can be defined as a "set of tools and procedures supporting the measurement process" [35, p. 347]. It describes the steps taken for data collection, recording, analysis, and presentation [35].

Nowadays, scholars agree on the value of such measurement systems as beneficial to innovation by helping to foster information exchange between actors [14], [36] and enhance decision making in teams [15]. However, concerning the design of such systems, some scholars argue that rigid forms of controls are needed to foster focus and speed in projects [37]. Others argue for more organic systems that allow for greater creativity and improvisation in teams [38]. For example, Amabiles' research on creativity in organizations [39] has revealed that while goal-setting and feedback are important drivers of creativity, they should not be deployed to control employees [21], as this could stifle their creative capabilities. Thus, a major challenge for practitioners and scholars seems to be the design of appropriate measurement instruments [37], specifically applying both qualitative and quantitative methods [35] and balancing creativity and efficiency to consider the specific requirements of both radical or incremental innovation efforts [14] .

To measure digital innovation, existing evidence is viewed alternatively as conflicting, scarce, or even non-existent [22], [23], [40]. This is specifically the case for DIUs [5], [12], and their adopted practices such as DT [10], [13]. For example, existing literature seems to overestimate the value of financial metrics while underestimating the importance of metrics for assessing added value beyond financial impact, such as customer centricity [22], [23]. Thus, digital innovation literature actively calls for "new forms of measuring success" $[22, p .6]$. This is especially the case for early phase innovation where only a few metrics are known, and scholars call for "further analysis [...] to derive front-end indicators [20, p. 17]. Accordingly, what is needed is a deeper understanding of the challenges involved in measuring digital innovation efforts.

\section{Research Methodology}

The aim of the study was to investigate the challenges faced by DIUs when measuring their DT activities related to digital innovation activities. Given the nascent nature of our topic, we adopted an exploratory qualitative research design to gain an in-depth understanding of the challenges DIUs experience in measuring their innovation efforts [41], [42]. We conducted 20 interviews with DIU employees across different industries, using a semi-structured interview guide. Following rigorous and established qualitative data analysis steps, we analyzed the interviews iteratively to gain a deeper understanding of our topic and derive patterns in our data [42]-[44].

\subsection{Sample Selection and Collection}

Taking into account the recent emergence of our phenomenon of interest and the limited number of available research subjects, we chose purposeful sampling as our sampling strategy [42], [45]. Between March and June 2020, twenty interviews were conducted with members of DIUs attached to incumbent organizations. Characteristics of the interviewees and their organizations are displayed in Figure 1. The average interview duration was 48 minutes.

\begin{tabular}{|c|c|c|c|c|}
\hline $\begin{array}{l}\text { Inter- } \\
\text { viewee }\end{array}$ & Industry & Role of Interviewee & $\begin{array}{l}\text { Tenure } \\
\text { (years) }\end{array}$ & Country \\
\hline IP_A & Pharma & Business Transformation Manager & 1 & GER \\
\hline IP_B & Healthcare & Innovation Coach & 5 & GER \\
\hline IP_C & Pharma & DIU Lead & 20 & GER \\
\hline IP_D & Pharma & Innovation Manager & 6 & GER \\
\hline IP_E & Insurance & Business Development Manager & 10 & GER \\
\hline IP_F & Pharma & CTO & 10 & GER \\
\hline IP_G & Insurance & Business Development Manager & 9 & GER \\
\hline IP_H & Pharma & $\mathrm{CIO}$ & 5 & GER \\
\hline IP_I & $\mathrm{CG}^{*}$ & DIU Lead & 9 & $\mathrm{CH}$ \\
\hline IP_J & Insurance & DIU Lead & 2 & $\mathrm{CH}$ \\
\hline IP_K & Energy & Innovation Coach & 2 & $\mathrm{CH}$ \\
\hline IP_L & $\mathrm{CG}^{*}$ & DIU Lead & 7 & $\mathrm{CH}$ \\
\hline IP_M & Mobility & Business Development Manager & 5 & $\mathrm{CH}$ \\
\hline PP_N & Energy & Innovation Manager & 4 & $\mathrm{CH}$ \\
\hline IP_O & $\mathrm{CG}^{*}$ & CEO & 3 & $\mathrm{CH}$ \\
\hline IP_P & Energy & DIU Lead & 2 & $\mathrm{CH}$ \\
\hline IP_Q & Telecom. & DIU Lead & 4 & $\mathrm{CH}$ \\
\hline IP_R & $\mathrm{CG}^{*}$ & Innovation Manager & 10 & $\mathrm{CH}$ \\
\hline IP_S & Energy & User Experience Designer & 3 & $\mathrm{CH}$ \\
\hline PP_T $_{-}$ & $\begin{array}{l}\text { Infra- } \\
\text { structure } \\
\text { Consumer }\end{array}$ & Innovation Manager & 1 & $\mathrm{CH}$ \\
\hline
\end{tabular}

Figure 1. Information about Interviewees 
The interviews followed a semi-structured interview guide, which was constantly adapted in light of the emerging categories, which informed further data collection [43], [45]. Our interview guide was structured into different areas. After introducing our research, we asked participants to give us an overview of the goal and strategy of their DIU and about their role within it. We then asked them about specific projects and activities and about how they measure and report on their activities. We were specifically interested in their understanding of DT, and in their level of expertise. Finally, we asked them to explain the challenges they experienced. As a pattern of challenges emerged around the topic of misalignment early on in interviewing, we were able to explore this aspect in more detail with subsequent interviewees.

\subsection{Data Analysis}

A grounded theory approach was adopted for analyzing our qualitative data, aiming to provide "rich descriptions of new phenomena", which has been stated to be a valuable theoretical contribution to the IS Community, alongside new theories or models [46]. First, we analyzed all interviews separately allowing us to gain a deep understanding of the challenges involved in using metrics in practice [47]. Following the Gioia Methodology, we coded relevant passages of the interview data, starting with 1st order codes and derived 2nd order codes [43]. An example of the derivation of a 2 nd order code from multiple 1st order codes is shown in Figure 2. Each passage was coded and analyzed by one researcher. To avoid subjective interpretation and to enhance the validity of our study [43], [44], a second researcher independently checked the coding. The final coding table was discussed and iterated multiple times to enhance rigor.

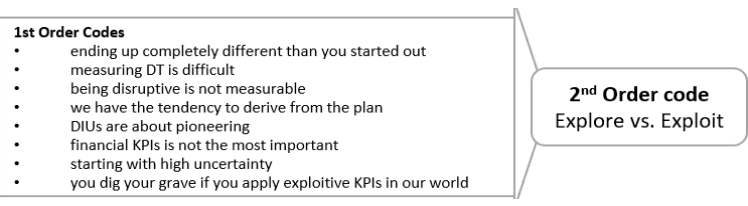

Figure 2. Exemplified Data Structure

\section{Results}

Our key finding was a misalignment identified between the aims of the DIU- or its supposed aims (DIU Objectives \& Scope), and the methods and metrics used to measure the activities of the DIU (Measurement System). An overview of both areas can be seen in Figure 3. Our 20 interviews revealed that this misalignment seems to create numerous challenges for the DIUs and their respective organizations. We focus only on challenges mentioned by more than one DIU to allow generalizability and describe the number of occurrences of these eight challenges.

\begin{tabular}{|c|c|c|}
\hline \multicolumn{3}{|c|}{ Areas of Misalignment } \\
\hline \multicolumn{3}{|c|}{ DIU Objectives \& Scope } \\
\hline Subarea & Challenge & Occurrence \\
\hline $\begin{array}{l}\text { A. Explore vs. } \\
\text { Exploit }\end{array}$ & $\begin{array}{l}\text { I: The intent for setting up a DIU lies } \\
\text { in pursuing exploratory activities but } \\
\text { the metrics applied are commonly used } \\
\text { to measure exploitative activities. }\end{array}$ & $\begin{array}{l}6 \\
\text { (IP_E, IP_J, } \\
\text { IP_L, IP_N, } \\
\text { IP_P, IP_H) }\end{array}$ \\
\hline $\begin{array}{l}\text { B. Innovation } \\
\text { vs. Trans- } \\
\text { formation }\end{array}$ & $\begin{array}{l}\text { II: DIUs contribute to the aim of } \\
\text { internal transformation, but metrics } \\
\text { like overall revenue or specific product } \\
\text { sales are used to assess the success of } \\
\text { the DIU, while no metrics for } \\
\text { transformation activities are in place. }\end{array}$ & $\begin{array}{c}6 \\
\text { (IP_A, IP_C, } \\
\text { IP_D, IP_E, } \\
\text { IP_G, IP_H) }\end{array}$ \\
\hline $\begin{array}{l}\text { C. Growth vs. } \\
\text { Focus }\end{array}$ & $\begin{array}{l}\text { III: Organizations expect the } \\
\text { diversification of a portfolio and } \\
\text { therefore multiple endeavors that can } \\
\text { be challenging to DIUs when trying to } \\
\text { deploy their resources to focus on } \\
\text { specific topics or projects. }\end{array}$ & $\begin{array}{c}3 \\
\text { (IP_B, IP_I, } \\
\text { IP_R) }\end{array}$ \\
\hline $\begin{array}{l}\text { D. Clear vs. } \\
\text { Unclear Intent }\end{array}$ & $\begin{array}{l}\text { IV: If no clear intent is set for } \\
\text { innovation activities, or the intent is } \\
\text { not stated or documented explicitly, } \\
\text { DIUs are measured on implicit and } \\
\text { possibly conflicting intents. }\end{array}$ & $\begin{array}{c}5 \\
(\text { IP_A, IP_B, } \\
\text { IP_N, IP_P, } \\
\text { IP_Q) }\end{array}$ \\
\hline \multicolumn{3}{|c|}{ Measurement System } \\
\hline Subarea & Challenge & Occurrence \\
\hline $\begin{array}{l}\text { E. Short-term } \\
\text { vs. Long term }\end{array}$ & $\begin{array}{l}\text { V: Exploring and creating new } \\
\text { ventures takes a long time, yet } \\
\text { innovation activities are often } \\
\text { measured short-term. }\end{array}$ & $\begin{array}{l}\text { 6 (IP_B, IP_C, } \\
\text { IP_F, IP_J, } \\
\text { IP_K, IP_N) }\end{array}$ \\
\hline $\begin{array}{l}\text { F. } \\
\text { Quantitative } \\
\text { vs. Quali- } \\
\text { tative }\end{array}$ & $\begin{array}{l}\text { VI: DIUs exploratory activities make it } \\
\text { hard to show financial metrics, } \\
\text { therefore they prefer to provide } \\
\text { insights with qualitative metrics. Yet } \\
\text { these are seen as critical and not as "as } \\
\text { valuable" by management. }\end{array}$ & $\begin{array}{l}10 \text { (IP_A,, } \\
\text { IP_D, IP_I, } \\
\text { IP_J, IP_K, } \\
\text { IP_M, IP_O, } \\
\text { IP_P, IP_S, } \\
\text { IP_T) }\end{array}$ \\
\hline $\begin{array}{l}\text { G. Standardi- } \\
\text { zation vs. } \\
\text { Flexibility }\end{array}$ & $\begin{array}{l}\text { VII: Highly specific innovation } \\
\text { activities demand flexibility in the } \\
\text { application of a metric, making it } \\
\text { difficult to find common factors with } \\
\text { which to compare different projects } \\
\text { through standardization. }\end{array}$ & $\begin{array}{c}5 \\
\text { (IP_B, IP_M, } \\
\text { IP_N, IP_P, } \\
\text { IP_T) }\end{array}$ \\
\hline $\begin{array}{l}\text { H. } \\
\text { Traceability } \\
\text { vs. Respons- } \\
\text { ibility }\end{array}$ & $\begin{array}{l}\text { VIII: Softer outcomes (e.g. creation of } \\
\text { new knowledge or capabilities for the } \\
\text { company) take time to develop and are } \\
\text { hard to trace back to the DIU over } \\
\text { time and the transfer gap between the } \\
\text { DIU and the owner corporation. }\end{array}$ & $\begin{array}{c}4 \\
\text { (IP_B, IP_D, } \\
\text { IP_K, IP_R) }\end{array}$ \\
\hline
\end{tabular}

Figure 3. Areas of Misalignment: DIU Objectives \& Scope and Measurement System 
In the following section, we describe each area in detail following a coherent structure. First, we explain the meaning of each subarea. Second, relying on our coding table, we provide more details based on sample quotes, indicated by the quote number (e.g. A1) for each subarea. Third, we summarize how and when this misalignment in a subarea or between subareas creates a specific challenge for the DIU and related stakeholders, such as the management of the mother company.

\subsection{DIU Objectives \& Scope}

Within the area of DIU Objectives \& Scope, we identified four subareas, which can create misalignment challenges for measuring innovation activities. The subareas are A) Explore vs Exploit, B) Innovation vs. Transformation, C) Growth vs. Focus, and D) Clear vs. Unclear Intent. The first and second-order codes as well as representative quotes are displayed in Table 1. Details are described in the following subsections.

4.1.1. Explore vs Exploit. Many DIUs see their goals in being explorative and identifying new opportunities for their organization. While our interviews confirmed this general intent, many explained that the exploratory nature of their activities can lead to different outcomes than what was planned in the beginning (e.g. A1, A2). For example, in one case the interviewee explained that they deploy methods such as DT for very explorative endeavors with open and unforeseeable results (A2). The interviewee explained that progress was measured in the later stages of the project based on metrics (e.g. ROI) used by management to compare and evaluate exploitative activities. Based on these metrics, however, early innovation projects cannot provide evidence for progress and thus show underperformance, which creates disappointment on both sides. This situation indicates that the team lacks the right metrics with which to prove and monitor their activities while management applies metrics that do not properly suit the project's aim.

Challenge I (6): The intent for setting up a DIU lies in pursuing exploratory activities, but the metrics applied are those commonly used for exploitative activities.

4.1.2. Innovation vs Transformation. Another area that can cause a misalignment when it comes to applying measurements lies in the initial intent of the DIU. For example, whether the DIU aims for an internal transformation or (mainly external) innovations, such as new products or services, was

Table 1. DIU Objectives \& Scope

\begin{tabular}{|c|c|c|}
\hline 2nd Order Code & 1st Order Code & Representative Quote \\
\hline \multirow[t]{2}{*}{$\begin{array}{l}\text { A. Explore vs. } \\
\text { Exploit }\end{array}$} & $\begin{array}{l}\text { DIUs are about } \\
\text { pioneering }\end{array}$ & $\begin{array}{l}\text { A1. Innovation is not about financial KPIs but about pioneering. But here in this context, it is difficult because [the } \\
\text { organization] probably looks primarily at the financial KPIs. But innovation is not, of course, first and foremost } \\
\text { about the earnings themselves, but rather about identifying new areas of earnings. [...]. If you measure a lab based } \\
\text { on financial figures, it's difficult [...]. (IP_N) }\end{array}$ \\
\hline & $\begin{array}{l}\text { ending up completely } \\
\text { differently to how you } \\
\text { started out }\end{array}$ & $\begin{array}{l}\text { A2. We did not specifically use [Measurements], it is difficult, I think, to do that. [...]. You know, the design thinking } \\
\text { process setup causes you to rethink and rethink and rethink as you're going through every stage. So, it's quite possible } \\
\text { that even with the application of design thinking, you know, you may end up with a completely different set of } \\
\text { requirements than you started with. (IP_H) }\end{array}$ \\
\hline \multirow[t]{3}{*}{$\begin{array}{l}\text { B. Innovation vs. } \\
\text { Transformation }\end{array}$} & $\begin{array}{l}\text { creating solutions } \\
\text { over changing } \\
\text { working modes }\end{array}$ & $\begin{array}{l}\text { B1. Nevertheless, I think that we [as human-centered innovation units] are usually approached to work out solutions } \\
\text { and not to change working methods.(IP_D) }\end{array}$ \\
\hline & $\begin{array}{l}\text { cold feet about } \\
\text { transformation due to } \\
\text { collapsed revenue }\end{array}$ & $\begin{array}{l}\text { B2. A huge topic and I think that's what happened to the numbers in the end. You just look at these numbers and you } \\
\text { see, ok, the revenue has collapsed in that area. [...] And now we are getting cold feet [about the transformation } \\
\text { project]. That's why we're doing it the way we've always done it. We're shutting it down. (IP_A) }\end{array}$ \\
\hline & $\begin{array}{l}\text { contribution to digital } \\
\text { transformation but not } \\
\text { seen as an assignment }\end{array}$ & $\begin{array}{l}\text { B3. Often such innovation labs contribute to digital transformation topics. Well, that was the same with us. [...] It was } \\
\text { implicitly the CEO's mission. You realize that we want to become more customer-centric, but with the people we now } \\
\text { have in marketing or product management, you can forget that. So you start things off, but that is actually not the } \\
\text { primary task. Well, that's what happens, that's what is wanted, but you can never take credit for this success. (IP_P) }\end{array}$ \\
\hline \multirow[t]{2}{*}{$\begin{array}{l}\text { C. Growth vs. } \\
\text { Focus }\end{array}$} & $\begin{array}{l}\text { finding focus with } \\
\text { few topics }\end{array}$ & $\begin{array}{l}\text { C1. At the moment there are two projects. [...] Two years ago almost everyone had a project, so about } 8 \text { projects in } \\
\text { parallel. But we have learned that we need a focus on a few topics. (IP_I) }\end{array}$ \\
\hline & $\begin{array}{l}\text { healthy shrinking vs } \\
\text { expected growth }\end{array}$ & $\begin{array}{l}\text { C2. [The organization] expected we can do more [than other departments of the organization]. But that's not the } \\
\text { case. Perhaps even more of a decline. Sort of a healthy shrinking. (IP_B) }\end{array}$ \\
\hline \multirow[t]{3}{*}{$\begin{array}{l}\text { D. Clear vs. } \\
\text { Unclear Intent }\end{array}$} & $\begin{array}{l}\text { organization does not } \\
\text { know what they want }\end{array}$ & $\begin{array}{l}\text { D1. The priorities are often very diverse. The motivation behind a project cannot be deduced. I think that's exactly the } \\
\text { problem in [our] Lab. [The organization] doesn't know exactly what they want from us either. (IP_N) }\end{array}$ \\
\hline & $\begin{array}{l}\text { that was not the } \\
\text { assignment }\end{array}$ & $\begin{array}{l}\text { D2. Much changed in the organization. But after two years they say: But that [transformation activites] wasn't your } \\
\text { assignment. }\left(I P \_P\right)\end{array}$ \\
\hline & $\begin{array}{l}\text { Why the project got } \\
\text { started is unclear }\end{array}$ & D3. Why we started this, well my boss did not really define that in a clear way. (IP_B) \\
\hline
\end{tabular}


raised as an important topic. One interviewee described how their activities, especially in the development of human-centered products and services, also contributed to transforming the mindset of the people they were working with. Even though the interviewee felt that their biggest impact had been to change the mindset of the team and related working modes, the unit was expected to create solutions (B1).

On a larger scale, this can mean that long-term transformation endeavors may get stopped due to a decrease in revenue. One participant explained that their transformation unit was evaluated after one year of work solely based on the revenue in their region (B2). No metrics were applied to measure the transformation activities directly.

In addition, it seems that transformation outcomes are not valued as highly as innovation outcomes. One participant indicated that they contributed strongly to an internal transformation, by becoming more customer-centric, but this was not assessed as a success metric for their unit (B3).

Challenge II (6): DIUs contribute to the aim of internal transformation, but metrics like overall revenue or specific product sales are used to assess the success of the DIU. No metrics for transformation activities are in place.
4.1.3. Focus vs Growth. Thirdly, we found different perceptions about how many projects a DIU should handle at the same time and whether a higher number of projects is indicative of the DIU performing well. On the contrary, one DIU, for example, started with eight projects, and over time reduced the number of projects to two because the DIU was unable to handle as many projects and, instead, chose to target its resources more effectively and efficiently $(\mathrm{C} 1)$.

It can become a challenge for a DIU if the organization expects the number of projects and outcomes from the DIU to grow, and compares it to other units of the organization working in different settings and with different objectives. One participant stated that the organization expected their unit to be able to do "more" than other units. At the same time, the unit itself focused on certain projects and was rather reduced in quantity to deliver quality $(\mathrm{C} 2)$.

To summarize, organizations associate DIUs with growth in terms of the number of projects and the speed of project delivery. As a result, they might evaluate the DIU's performance negatively if the DIU focuses its efforts on fewer projects in order to increase its efficiency and effectiveness.

Challenge III (3): Organizations expect a diversification of the portfolio and therefore multiple endeavors that can be challenging to DIUs when they try to deploy their resources to focus on specific topics or projects.

Table 2. Measurement System

\begin{tabular}{|c|c|c|}
\hline 2nd Order Code & 1st Order Code & Representative Quote \\
\hline \multirow[t]{3}{*}{$\begin{array}{l}\text { E. Short-term } \\
\text { vs. Long term }\end{array}$} & $\begin{array}{l}\text { CFO wants to see } \\
\text { short term results }\end{array}$ & $\begin{array}{l}\text { E1. Especially in front of the CFO, who also wants to see results in the short term, it is sometimes difficult to argue } \\
\text { for the long term. We also learn a lot here in the lab that we could transfer to the company. (IP_I) }\end{array}$ \\
\hline & $\begin{array}{l}\text { HCD methods create a } \\
\text { higher effort in the } \\
\text { short term }\end{array}$ & $\begin{array}{l}\text { E2. Well, actually the effort came at the end of projects [because we had to adjust to users need we did not plan for in } \\
\text { the beginning], and with using Design Thinking now, the effort came at the beginning of the project. So it seems to be } \\
\text { more effort if you just look short term. (IP_B) }\end{array}$ \\
\hline & proof of present value & $\begin{array}{l}\text { E3. We create a new idea or a new project proposal. Even if it is good we get asked, what is the present value? } \\
\left(I P \_C\right)\end{array}$ \\
\hline \multirow[t]{2}{*}{$\begin{array}{l}\text { F. Quantitative } \\
\text { vs. Qualitative }\end{array}$} & $\begin{array}{l}\text { top management } \\
\text { expects hard KPIs }\end{array}$ & $\begin{array}{l}\text { F1. Soft KPIs are extremely subjective. It's quite elusive. The reliability of the key figures is therefore also much less } \\
\text { there. The higher you go in the hierarchy level in a corporation, the more hard KPIs are needed. "(IP_N) }\end{array}$ \\
\hline & $\begin{array}{l}\text { sales figures are } \\
\text { counterproductive at } \\
\text { an early stage }\end{array}$ & $\begin{array}{l}\text { F2. The expectations were that they wanted numbers. I have worked towards that in the last years that we have the } \\
\text { construct where this is no longer so. So with the construct, we have created free space. It needs pressure. Pressure's } \\
\text { okay. But it doesn't need the pressure of sales at a very early stage. It's counterproductive. (IP_P) }\end{array}$ \\
\hline \multirow[t]{3}{*}{$\begin{array}{l}\text { G. } \\
\text { Standardization } \\
\text { vs. Flexibility }\end{array}$} & $\begin{array}{l}\text { middle ground needed } \\
\text { between } \\
\text { standardization and } \\
\text { freedom }\end{array}$ & $\begin{array}{l}\text { G1. I'm not a fan of pre-defined dashboards, it's more like reporting things just to report them. I think that's a big } \\
\text { weakness of it. But I do understand that if the KPIs are not standardized, some teams will somehow slip through. So } \\
\text { there has to be a middle ground as a solution. [...]. It has to be very modular and every Innovation Lab has to build } \\
\text { its own matrix from it. [...] When we need comparative values, we always find it very difficult. (IP_M) }\end{array}$ \\
\hline & $\begin{array}{l}\text { project-specific hard } \\
\text { to generalize }\end{array}$ & $\begin{array}{l}\text { G2. In any case, non-financial indicators are also needed. However, the KPIs are very different-especially the } \\
\text { project-specific KPIs are difficult to generalize. It depends very much on the ideas. I think it might be getting too } \\
\text { generic. It can be advantageous to determine the KPIs yourself, for your own understanding. You should always ask } \\
\text { yourself which KPIs are relevant to us. (IP_N) }\end{array}$ \\
\hline & $\begin{array}{l}\text { you cannot trace } \\
\text { success back to DIU }\end{array}$ & $\begin{array}{l}\text { G3. "[...] surely the [project] will somehow be reflected in these areas, but you can hardly trace it back [to what we } \\
\text { did, specifically]." (IP_B) }\end{array}$ \\
\hline \multirow{2}{*}{$\begin{array}{l}\text { H. Traceability } \\
\text { vs. } \\
\text { Responsibility }\end{array}$} & effects get diluted & $\begin{array}{l}\text { H1. In the meantime, however, they are again in other meetings on other topics with other people, where what they } \\
\text { have just experienced is probably being diluted a bit. (IP_D) }\end{array}$ \\
\hline & $\begin{array}{l}\text { organization does not } \\
\text { understand or } \\
\text { implement ideas }\end{array}$ & $\begin{array}{l}\text { H2. We have evolved but [the organization] has not. Measuring cultural conditions is important. What use is a good } \\
\text { lab with good ideas, within a company that is not able to understand and implement these ideas? The transformation } \\
\text { process from lab to [organization] would have to be made measurable somehow. (IP_K) }\end{array}$ \\
\hline
\end{tabular}


4.1.4. Clear vs Unclear Intent. One last area of misalignment occurs when there is little or no clarity about what the DIU is supposed to achieve. In larger organizations, there are multiple priorities and political opinions at play, making it hard for the DIU to identify its supposed goals. One participant described how the motivation behind a project is hard to identify due to the multiple perspectives in the organization (D1). For him, there was no clear intent of what the organization wanted the DIU to achieve.

Sometimes implicit expectations are placed upon the innovation activities, but when it comes to measurement and evaluation, these are no longer considered. As found in one DIU, where the intent was never explicitly stated, misalignment occurs when applying metrics after a long time that might not fit the (assumed) intent (D2).

Challenge IV (5): If no clear intent is set for innovation activities, or the intent is not clearly stated or documented, DIUs are measured on implicit and possibly conflicting aims.

\subsection{Measurement System}

The second part of Figure 1 explains how DIU's are assessed by using metrics to measure their digital innovation activities. We termed that Measurement System and identified this as a second area of misalignment. Subareas within the Measurement System are E) Short Term vs. Long Term, F) Quantitative vs. Qualitative, G) Standardization vs. Flexibility and H) Traceability vs. Responsibility. An overview of the subareas and exemplifying quotes are provided in Table 2. More descriptive detail is given in the following subsections.

4.2.1. Short Term vs. Long Term. We found a conflict between DIUs and their organizations concerning the timeline. For example, one interviewee explained a perceived shift in effort and time intensity, when working in exploratory mode for example with Design Thinking. In previous activities, they intensified their effort at the end of the project, when they needed to make adjustments for unplanned user requirements. But working with DT from the start, this meant shifting to a perceived higher effort right from the beginning. If measures are applied short term, it seems like a less effective way of working, not taking into account potential effectiveness at a later point in time (E2). In another case, when presenting results to the management board, the CEO wanted to see short-term results that were difficult to provide for a lab that aimed to accumulate and transfer knowledge for the mother company (E1).

To summarize the interview statements, we find that many innovation activities are on a long-term horizon and aim to provide long term value. However, members of the organization are inclined to apply financial metrics from early on, when the project still needs more time to produce a product or a service that can generate financial income. According to our interviewees, this presents a major challenge for the team of a DIU.

Challenge V (6): Exploring and creating new ventures takes a long time, yet innovation activities are often measured short-term.

4.2.2. Quantitative vs. Qualitative. Similar challenges could be observed when it comes to the provision of results based on qualitative or quantitative outcomes. One interviewee explained when reporting to higher management, quantitative metrics are expected and perceived as the key data for decision making (F1). Another participant revealed that they took a long time to convince management not to expect quantitative metrics early on. The interviewee explained that pressure from management was okay, but looking at the generated sales too close to the beginning of the project is very counterproductive (F2).

Our findings show two things. First, management seems critical when it comes to evaluating a DIU (or anything else, for the matter) based only on qualitative data. Second, DIU's are willing to provide insights but want to rely on qualitative data. This also makes sense as DIUs prefer a setup where they can focus on their exploratory endeavors in which it can be hard to show a financial metric. Management, on the other hand, is used to evaluating projects based on quantitative metrics as they do so in their exploitative business world. This translates into a critical attitude towards qualitative metrics which are seen as too subjective.

Challenge VI (10): DIUs' exploratory activities make it hard to show progress with financial metrics, which is why they prefer qualitative metrics. Yet these are not sufficiently appreciated by management or seen "as valuable" as hard data.

4.2.3. Standardization vs. Flexibility. The question of standardization and flexibility concerning measurement systems arises as one of the areas of misalignment between the DIU and the organization. One interviewee explained that due to the high diversity of projects, it is difficult to track standardized metrics (G2). While one member understood the necessity of using comparable metrics, the participant also stated 
that in the end, only the project team itself can define the metrics that are necessary to keep track of activities (G2). Thus, DIUs endeavors can be highly specific and of great variety, making it rather difficult for the organization to compare different projects or activities based on common metrics.

Closely connected to the standardization vs. flexibility dilemma, we found that DIUs experience difficulties when they need to distinguish between the purpose of using metrics. The choice of metrics can vary depending on whether its purpose is external reporting or part of internal monitoring activities.

Challenge VII (5): Highly specific innovation activities demand flexibility in the application of metrics, which makes finding common ground for comparison with other projects more difficult.

4.2.4. Traceability vs. Responsibility. As the last subarea, we identified Traceability vs Responsibility. This refers to challenges occurring due to the difficulty in identifying the source of outcomes and to explain causality demonstrating the performance of the DIU.

One participant describes how employees create new knowledge or develop capabilities due to activities in the DIU. When they start to share it with other employees in the organization, it is often difficult to trace this back. Therefore learning and development as a performance criterion seems difficult (H1).

In addition, one source of misalignment is the transfer gap between the DIU and the organization. One case described the situation in which the DIU creates good ideas and outcomes, but the organization does not implement them (H2). If the DIU is subsequently measured on financial metrics, depending on the implementation of ideas as products or services on the market, the DIU does not seem to perform-whereas the DIU sees their outcome as successful, as they have contributed new ideas.

Challenge VIII (4): Softer outcomes such as creating knowledge or capabilities for the company take time to develop and are hard to trace back to the DIU over time, due to the transfer gap between the DIU and the mother firm.

\section{Discussion}

Our study identified eight key challenges that DIUs experience when measuring DT related innovation activities, related to the misalignment between the DIUs' Objectives and Scope and the applied Measurement Systems. The following paragraphs discusses the three most named challenges in more detail. The most mentioned challenge concerned the need of DIUs to be measured qualitatively, which conflicts with the wish from management to apply quantitative measures (challenge VI). Existing literature explains that for more exploratory endeavors, qualitative measurement techniques seem to be more suitable as endeavors with less precision and specificity reduce the ability to use quantitative metrics [35], [48]. This connects with challenge V (short-term vs. long-term) and with literature showing a preference for established metrics applied for short term horizons [18], [49]. As this is the case for DIUs, it might not be beneficial to adapt simple diagnostic measurement systems [35], [48]. Another frequently mentioned challenge was Challenge I, which stated that DIUs aim for exploratory activities [50] while they are assessed on a measurement system more suited for exploitative activities. Analyzing these exploratory activities with a closer lens and taking the example of DT reveals that such methods are deployed extensively. However, their measurement seems to be complex as key concepts such as iteration or human-centeredness are difficult to translate into metrics and their effects are difficult to trace [10], [13]. Looking beyond the viability and feasibility of a new venture and considering the desirability on the measurement level seems necessary. This connects well with calls for new measurement models due the impact of digital innovation [12]. Thus, scholars stress the need to develop measurement systems that allow to show added value beyond a financial gain such as customer centricity [23].

In addition, our findings show that to apply measurements in a beneficial manner, it is not just necessary to look at the metrics and their implementation but also consider inputs such as careful planning and communication from the beginning [16]. As can be seen in challenge IV, the objectives and the general intent of innovation activities should be clarified explicitly from the start which is also in line with earlier research on creativity in organizations, suggesting the importance of goal-setting and feedback mechanisms [21]. This does not mean that the outcome needs to be defined from the outset, as this would be contradicting the exploratory and open-ended nature of DIUs, but that stating a clear intent helps to avoid conflicting assumptions. Otherwise this can create tensions at a later point in time, when metrics are applied that have neither been planned for, nor are appropriate for the nature of DIUs' purpose. 


\section{Conclusion}

This study investigated the challenges faced by DIUs when measuring DT-related digital innovation activities. We answer the research question by presenting rich descriptions of areas of misalignment and describing eight specific challenges, which create challenges for DIUs to adequately measure their innovation activities [46]. In doing so we enhance the understanding of current struggles of DIUs in measuring their activities and evaluating their success in the pursuit of their goals. Gaining a rich understanding of these challenges is the first step to creating measurements that are better suited to digital innovation endeavors, especially of those with an exploratory focus. Our findings imply that, to prove their value to the organization, DIUs and their owner organizations need to create a fit between the exploratory-often long-term -objectives, and the measurements.

In terms of limitations, our sample stems from Germany and Switzerland. We did not consider industry specifics in our sampling strategy, to allow for a broader scope. For future research it might seem particularly interesting to investigate in more detail how DIUs actually manage and steer DT-related digital innovation activities. We need more research to understand and explain the value that DIUs are providing beyond financial metrics. In addition, DIUs need to translate the organizational implications of digital innovation into actual metrics and frameworks that firms can use to pursue the development of digital innovation.

\section{Acknowledgement}

We kindly thank Céline Stadler for her support in gathering data and the Hasso Plattner Design Thinking Research Program for funding our research generously enabling us to investigate this topic.

\section{References}

[1] S. Nambisan, K. Lyytinen, A. Majchrzak, and M. Song, "Digital innovation management: Reinventing innovation management research in a digital world," Miss. Q., vol. 41, no. 1, pp. 223-238, Mar. 2017.

[2] Y. Yoo, O. Henfridsson, and K. Lyytinen, "Research Commentary-The New Organizing Logic of Digital Innovation: An Agenda for Information Systems Research," Information Systems Research, vol. 21, no. 4, pp. 724-735, Dec. 2010.
[3] M. E. Porter and J. E. Heppelmann, "How smart, connected products are transforming companies," Harv. Bus. Rev., vol. 93, no. 10, pp. 96-114, 2015.

[4] Y. Yoo, R. J. Boland, K. Lyytinen, and A. Majchrzak, "Organizing for Innovation in the Digitized World," Organization Science, vol. 23, no. 5, pp. 1398-1408, Oct. 2012.

[5] P. Barthel, C. Fuchs, B. Birner, and T. Hess, "Embedding Digital Innovations in Organizations: A Typology for Digital Innovation Units," in WI2020, GITO Verlag, 2020, pp. 780-795.

[6] A. Hund, F. Holotiuk, H.-T. Wagner, and D. Beimborn, "Knowledge Management in the Digital Era: How Digital Innovation Labs Facilitate Knowledge Recombination," 2019,

[7] F. Holotiuk and D. Beimborn, "Organizational Ambidexterity for Digital Innovation: The Approach of Digital Innovation Labs," Global Proc, vol. Surrey, no. 2018, p. 22, Apr. 2018.

[8] T. Brown, "Design thinking," Harvard Business Review, vol. 86, no. 6, pp. 84-92, 141, Jun. 2008.

[9] C. Vetterli, F. Uebernickel, W. Brenner, C. Petrie, and D. Stermann, "How Deutsche Bank's IT Division Used Design Thinking to Achieve Customer Proximity," MIS Quarterly Executive, vol. 15, no. 1, 2016, [Online].

[10] P. Micheli, S. J. S. Wilner, S. H. Bhatti, M. Mura, and M. B. Beverland, "Doing Design Thinking: Conceptual Review, Synthesis, and Research Agenda," J Prod Innov Manag, vol. 36, no. 2, pp. 124-148, Mar. 2019.

[11] F. Holotiuk and D. Beimborn, "Temporal Ambidexterity: How Digital Innovation Labs Connect Exploration and Exploitation for Digital Innovation," 2019, Accessed: Jun. 30, 2020. [Online].

[12] J. Frey, F. Holotiuk, and D. Beimborn, "Debating Digital Innovation: A Literature Review on Realizing Value from Digital Innovation," WI2020 Zentrale Tracks, 2020.

[13] L. Carlgren, I. Rauth, and M. Elmquist, "Framing Design Thinking: The Concept in Idea and Enactment: Creativity and Innovation Management," Creativity and Innovation Management, vol. 25, no. 1, pp. 38-57, Mar. 2016.

[14] A. Davila, G. Foster, and D. Oyon, "Accounting and Control, Entrepreneurship and Innovation: Venturing into New Research Opportunities," European Accounting Review, vol. 18, no. 2, pp. 281-311, Jun. 2009.

[15] D. S. Bedford, J. Bisbe, and B. Sweeney, "Performance measurement systems as generators of cognitive conflict in ambidextrous firms," Accounting, Organizations and Society, vol. 72, pp. 21-37, Jan. 2019.

[16] J. Poskela and M. Martinsuo, "Management Control and Strategic Renewal in the Front End of Innovation," Journal of Product Innovation Management, vol. 26, no. 6, pp. 671-684, Nov. 2009.

[17] R. S. Kaplan, D. P. Norton, and Others, "The balanced scorecard: measures that drive performance," Harv. Bus. Rev., vol. 83, no. 7, p. 172, 2005.

[18] T. Davila, M. Epstein, and R. Shelton, Making Innovation Work: How to Manage It, Measure It, and Profit from It, Updated Edition. FT Press, 2012. 
[19] I. P. McCarthy and B. R. Gordon, “Achieving contextual ambidexterity in R\&D organizations: a management control system approach," R\&D Management, vol. 41, no. 3, pp. 240-258, Jun. 2011.

[20] M. Dziallas and K. Blind, "Innovation indicators throughout the innovation process: An extensive literature analysis," Technovation, vol. 80-81, pp. 3-29, Feb. 2019.

[21] B. A. Hennessey and T. M. Amabile, "Creativity," Annu. Rev. Psychol., vol. 61, pp. 569-598, 2010.

[22] A. Hund, K. Drechsler, and V. A. Reibenspiess, "The current state and future opportunities of digital innovation: A literature review," Stockholm \& Uppsala, Sweden, June 8-14, 2019, Accessed: Jun. 25, 2020.

[23] E. Brynjolfsson and J. Oh, "The Attention Economy: Measuring the Value of Free Digital Services on the Internet," presented at the ICIS, 2012, Accessed: Jul. 02, 2020.

[24] J. Huang, O. Henfridsson, M. J. Liu, and S. Newell, "Growing on steroids: Rapidly scaling the user base of digital ventures through digital innovation," Miss. Q., vol. 41, no. 1, 2017, [Online].

[25] R. Kohli and N. P. Melville, "Digital innovation: A review and synthesis," Information Systems Journal, vol. 29, no. 1, pp. 200-223, Jan. 2019.

[26] R. G. Fichman, B. L. Dos Santos, and Z. (eric) Zheng, "Digital Innovation as a Fundamental and Powerful Concept in the Information Systems Curriculum," Miss. Q., vol. 38, no. 2, pp. 329-A15, 2014.

[27] J.-P. Raabe et al., "Digital Innovation Units: Exploring Types, Linking Mechanisms and Evolution Strategies in Bimodal IT Setups," in WI2020 Zentrale Tracks. (2020), 2020, pp. 844-858.

[28] F. Dobrigkeit and D. de Paula, "Design thinking in practice: understanding manifestations of design thinking in software engineering," in Proceedings of the 2019 27th ACM Joint Meeting on European Software Engineering Conference and Symposium on the Foundations of Software Engineering, Tallinn, Estonia, Aug. 2019, pp. 1059-1069, Accessed: Jul. 13, 2020.

[29] W. Brenner and F. Uebernickel, Eds., Design Thinking for Innovation. Cham: Springer, 2016.

[30] W. Brenner, F. Uebernickel, and T. Abrell, "Design Thinking as Mindset, Process, and Toolbox," in Design Thinking for Innovation, 2016, pp. 3-21.

[31] R. L. Martin, The Design of Business: Why Design Thinking is the Next Competitive Advantage. Harvard Business Press, 2009.

[32] T. Schumacher and S. Mayer, "Preparing Managers for Turbulent Contexts: Teaching the Principles of Design Thinking," Journal of Management Education, vol. 42, no. 4, pp. 496-523, Aug. 2018.

[33] A. Mabogunje and L. J. Leifer, "210-NP: measuring the mechanical engineering design process," in Technology-Based Re-Engineering Engineering Education Proceedings of Frontiers in Education FIE'96 26th Annual Conference, Nov. 1996, vol. 3, pp. 1322-1328 vol.3.

[34] M. Dolata, F. Uebernickel, and G. Schwabe, "The power of words: Towards a methodology for progress monitoring in design thinking projects," 2017, Accessed: Jan. 23, 2020. [Online].

[35] I. C. Kerssens-van Drongelen and A. Cooke, "Design principles for the development of measurement systems for research and development processes," R\&D Management, vol. 27, no. 4, pp. 345-357, Oct. 1997.

[36] M. Ylinen and B. Gullkvist, "The effects of organic and mechanistic control in exploratory and exploitative innovations," Management Accounting Research, vol. 25, no. 1, pp. 93-112, Mar. 2014.

[37] P. Lill, A. Wald, and M. J. Christoph, "In the field of tension between creativity and efficiency: a systematic literature review of management control systems for innovation activities," European Journal of Innovation Management, Jan. 2020,

[38] D. Dougherty, "Interpretive Barriers to Successful Product Innovation in Large Firms," Organization Science, vol. 3, no. 2, pp. 179-202, May 1992.

[39] T. M. Amabile, R. Conti, H. Coon, J. Lazenby, and M. Herron, "Assessing the Work Environment for Creativity," AMJ, vol. 39, no. 5, pp. 1154-1184, Oct. 1996.

[40] H. Edison, N. bin Ali, and R. Torkar, "Towards innovation measurement in the software industry," J. Syst. Softw., vol. 86, no. 5, pp. 1390-1407, May 2013.

[41] R. K. Yin, "Case study research: Design and methods. Sage publications," Thousand oaks, 2009.

[42] A. C. Edmondson and S. E. Mcmanus, "Methodological fit in management field research," AMRO, vol. 32, no. 4, pp. 1246-1264, Oct. 2007.

[43] D. A. Gioia, K. G. Corley, and A. L. Hamilton, "Seeking Qualitative Rigor in Inductive Research: Notes on the Gioia Methodology," Organizational Research Methods, vol. 16, no. 1, pp. 15-31, Jan. 2013.

[44] A. Strauss and J. Corbin, Basics of qualitative research techniques. Sage publications Thousand Oaks, CA, 1998.

[45] K. M. Eisenhardt, "Building Theories from Case Study Research,” AMRO, vol. 14, no. 4, pp. 532-550, Oct. 1989.

[46] M. Wiesche, M. C. Jurisch, P. W. Yetton, and H. Krcmar, "Grounded theory methodology in information systems research,” Miss. Q., vol. 41, no. 3, pp. 685-701, 2017.

[47] R. E. Stake, Multiple Case Study Analysis. Guilford Press, 2013.

[48] D. S. Bedford, "Management control systems across different modes of innovation: Implications for firm performance," Management Accounting Research, vol. 28, pp. 12-30, Sep. 2015.

[49] A. Godener and K. E. Soderquist, "Use and impact of performance measurement results in R\&D and NPD: an exploratory study," R\&D Management, vol. 34, no. 2, pp. 191-219, Mar. 2004.

[50] L. Göbeler, D. Schaar, and P. Hukal, "Initiating Ambidexterity through Digital Innovation Labs," in Proceedings of the 28th European Conference on Information Systems (ECIS): A Virtual AIS Conference, 2020 , p. 55. 